\title{
Investigation of Gamma Radiation Shielding Properties of Some Zinc Tellurite Glasses
}

\author{
Shams Issa, ${ }^{1,2^{*}}$ Mohamad Sayyed $^{2}$ and Murat Kurudirek ${ }^{3}$ \\ ${ }^{1}$ Physics Department, Faculty of Science, Al-Azhar University, \\ 71524 Assiut, Egypt \\ ${ }^{2}$ Physics Department, Faculty of Science, University of Tabuk, \\ 71491 Tabuk, Saudi Arabia \\ ${ }^{3}$ Faculty of Science, Department of Physics, Ataturk University, \\ 25240 Erzurum, Turkey \\ *Corresponding author: shams_issa@yahoo.com
}

Published online: 25 November 2016

To cite this article: Issa, S. et al. (2016). Investigation of gamma radiation shielding properties of some zinc tellurite glasses. J. Phys. Sci., 27(3), 97-119, http://dx.doi.org/10.21315/jps2016.27.3.7

To link to this article: http://dx.doi.org/10.21315/jps2016.27.3.7

\begin{abstract}
The mass attenuation coefficient $\left(\mu_{m}\right)$, half-value layer $(H V L)$ and mean free path for $x \mathrm{ZnO}-(100-x) \mathrm{TeO}_{2}$, where $\mathrm{x}=10,20,30$, and $40 \mathrm{~mol} . \%$, have been measured with 0.662, 1.173 and $1.33 \mathrm{MeV}$ photons emitted from ${ }^{137} \mathrm{Cs}$ and ${ }^{60} \mathrm{Co}$ using a $3 \times 3$ inch $\mathrm{NaI}(\mathrm{Tl})$ detector. Some relevant parameters, such as the effective atomic numbers $\left(Z_{e f f}\right)$ and electron densities $\left(N_{e l}\right)$, of the glass samples have also been calculated in the photon energy range of 0.015-15 MeV. Moreover, exposure buildup factors (EBF) were estimated using the five-parameter Geometric Progression (G-P) fitting approximation for penetration depths up to 40 times the mean free path and within the same energy range of 0.015-15 MeV. The measured mass attenuation coefficients were found to agree satisfactorily with the theoretical values obtained using WinXCom. The effective atomic numbers $\left(Z_{e f f}\right)$ and electron densities $\left(N_{e l}\right)$ were found to be the highest for a 40ZnO-60TeO $\mathrm{Z}_{2}$ glass in the energy range of $0.04-0.2 \mathrm{MeV}$. The $10 \mathrm{ZnO}-90 \mathrm{TeO}$ glass sample had lower values of gamma ray exposure buildup factors in the intermediate energy region. These data on the radiation shielding characteristics of zinc tellurite glasses may be useful for the design of gamma radiation shields.
\end{abstract}

Keywords: Mass attenuation coefficient, effective atomic number, electron density, exposure buildup factors, tellurite glass 


\section{INTRODUCTION}

High-energy gamma rays are a type of electromagnetic radiation, emitted by radioisotopes or other radiation sources, that can travel distances of many kilometres within seconds. Gamma ray emitting isotopes have been used extensively in many fields, such as industry, agriculture and medicine. It is very important to develop effective mixtures of materials that can act as shields against such nuclear radiation. ${ }^{1-3}$ Materials having high atomic-number constituents, such as tellurite $(Z=52)$, are widely used in radiation shields due to their strong attenuation of $\mathrm{X}$-rays, gamma rays and fast neutrons. ${ }^{4}$ The preparation and modification of transparent glasses are essential for the development of a proper radiation shield. Tellurites transmit wavelengths in the range of $0.5 \mu \mathrm{m}$ to $6 \mu \mathrm{m}$, display good mechanical and thermal stability and are not photosensitive. ${ }^{5-9}$ The addition of $\mathrm{ZnO}$ to tellurite increases glass formation and thermal stability. ${ }^{10,11}$

The gamma radiation shielding properties of different compounds were evaluated using parameters, such as mass attenuation coefficient $\left(\mu_{\mathrm{m}}\right)$, half-value layer (HVL), effective atomic number $\left(\mathrm{Z}_{\mathrm{eff}}\right)$, electron density $\left(\mathrm{N}_{\mathrm{el}}\right)$ and buildup factors (BFs). ${ }^{12}$ The EBF refers to the exposure in the air after penetration through the absorber or shielding material. Since a primary assessment of radiation protection is the exposure field before and after the use of a radiation shield, exposure buildup factors are often of more general use, with appropriate adjustments for air exposure, to obtain the absorbed dose. ${ }^{13}$ The build-up factor values have been computed by various codes, such as the Geometric Progression (GP) method, ${ }^{14}$ iterative method, ${ }^{15}$ invariant embedding method, ${ }^{16,17}$ and Monte Carlo method. ${ }^{18}$ The American National Standards ANSI/ANS 6.4.3 ${ }^{19}$ used a GP fitting method and provided build-up factor data for 23 elements, along with water, air and concrete, at 25 standard energies in the energy range of $0.015-15 \mathrm{MeV}$, with suitable intervals, up to a penetration depth of 40 mean free paths.

While several studies have been performed to investigate the degree of radiation attenuation in different glass samples, ${ }^{20-25}$ the radiation shielding characteristics of the selected zinc tellurite glasses have not yet been investigated yet, which prompted us to carry out this work. In the present work, the mass attenuation coefficients were measured for tellurite glasses at photon energies of $0.662,1.173$ and $1.33 \mathrm{MeV}$. The effective atomic numbers $\left(\mathrm{Z}_{\mathrm{eff}}\right)$ and electron densities $\left(\mathrm{N}_{\mathrm{el}}\right)$ of the glass samples were calculated in the energy range of $0.015-15 \mathrm{MeV}$. The gamma ray exposure buildup factors (EBF) of the glass systems were computed for penetration depths up to 40 mean free paths in the energy range of $0.015-15 \mathrm{MeV}$. 


\section{EXPERIMENTAL}

\subsection{Sample Preparation}

The glass systems made of composite $x \mathrm{ZnO}-(100-x) \mathrm{TeO}_{2}$, where $x=10,20,30$, and $40 \mathrm{~mol} \%$, were prepared by a rapid melt quenching technique using $\mathrm{TeO}_{2}$ and $\mathrm{ZnO}(99.99 \%)$. Exact mole ratios of the reactants were mixed thoroughly with an agate mortar. The mixtures were initially heated in a ceramic crucible in an electrical muffle furnace at $1073 \mathrm{~K}$ for $60 \mathrm{~min}$, and the melt was swirled frequently to ensure proper mixing and homogeneity. The melt was then quenched to room temperature. The obtained samples were annealed by transferring them into another electrical furnace at a temperature of $1623 \mathrm{~K}$ for $4 \mathrm{~h}$ and slowly cooling to room temperature to minimise the cracking and thermal stress of the glasses. ${ }^{26-28}$ The samples were prepared with different thicknesses $(0.5-1.3 \mathrm{~cm})$. The relative error in the thickness was found to be $\pm 0.002 \mathrm{~cm}$. The densities of the prepared glassy samples were determined by the Archimedes method via immersion in a liquid, such as acetone. The chemical composition of the glass samples, densities, molar volume and thickness are listed in Table 1.

Table 1: Chemical composition, density, molar volume $\left(\mathrm{M}_{\mathrm{v}}\right)$ and thickness of glass samples.

\begin{tabular}{cccccc}
\hline Sample & \multicolumn{2}{c}{ Composition (mole fraction) } & \begin{tabular}{c} 
Density \\
\cline { 2 - 3 }$\left(\mathrm{g} \mathrm{cm}^{-3}\right)$
\end{tabular} & $\begin{array}{c}\mathrm{M}_{\mathrm{v}} \\
\left(\mathrm{cm}^{3} \mathrm{~mol}^{-1}\right)\end{array}$ & $\begin{array}{c}\text { Thickness } \\
(\mathrm{cm})\end{array}$ \\
\hline 1 & 10 & 90 & $5.048 \pm 0.050$ & 30.067 & 0.523 \\
2 & 20 & 80 & $5.101 \pm 0.051$ & 28.221 & 0.752 \\
3 & 30 & 70 & $5.149 \pm 0.051$ & 26.439 & 0.912 \\
4 & 40 & 60 & $5.181 \pm 0.052$ & 24.766 & 1.321 \\
\hline
\end{tabular}

*The relative error in the thickness error was found as $\pm 0.002 \mathrm{~cm}$

\subsection{Measurements}

The mass attenuation coefficient measurements were performed with a gamma ray spectrometer, which employed a scintillation detector $(3 \times 3$ inch) (Figure 1). The hermetically sealed assembly included a high-resolution $\mathrm{NaI}(\mathrm{Tl})$ crystal, photomultiplier tube, internal magnetic/light shield, aluminium housing and a 14pin connector coupled to PC-MCA Canberra Accuspec. It had the following specifications: (1) resolution 7.5\%, specified at the $662 \mathrm{keV}$ peak of ${ }^{137} \mathrm{Cs}$; (2) an aluminium window $0.5 \mathrm{~mm}$ thick, with a density of $147 \mathrm{mg} \mathrm{cm}^{-2}$; (3) a $1.6 \mathrm{~mm}$ thick reflector oxide with a density of $88 \mathrm{mg} \mathrm{cm}^{-2}$; (4) a conical lined steel magnetic/light shield; and (5) a +902 volt DC operating voltage. A dedicated software program, Genie 2000 from Canberra, was used to carry out the on-line 
analysis of each measured gamma ray spectrum. The detection array was energy calibrated using ${ }^{60} \mathrm{Co}(1173.2$ and $1332.5 \mathrm{keV}),{ }^{133} \mathrm{Ba}(356.1 \mathrm{keV})$ and ${ }^{137} \mathrm{Cs}$ (661.9 keV).

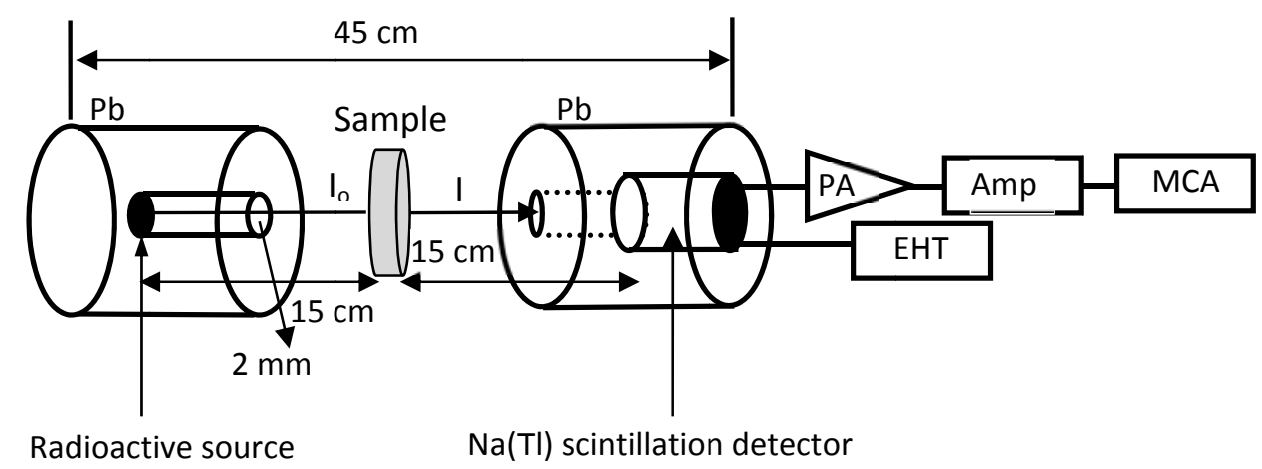

Figure 1: Narrow beam experiment geometry.

The experimental mass attenuation coefficients $\left(\mu_{\mathrm{m}}\right)$ of the glass samples have been measured by the well-known Beer-Lambert equation:

$$
\mu_{m}=\frac{\ln \left(I_{o} / I\right)}{\rho t}
$$

Where $I_{0}$ and $I$ are the incident and transmitted intensities, $\rho$ is the density of material $\left(\mathrm{g} \mathrm{cm}^{-3}\right)$ and $\mathrm{t}$ is the thickness of the absorber $(\mathrm{cm})$. The glass samples were irradiated by $0.662,1.173$ and $1.33 \mathrm{MeV}$ photons from $5 \mu \mathrm{Ci}{ }^{13.7} \mathrm{Cs}$ and ${ }^{60} \mathrm{Co}$ radioactive sources. The measurements were taken for four hours and were repeated 5 times for each sample.

\section{CALCULATIONS}

\subsection{Effective Atomic Number and Electron Density}

The total photon interaction cross section $\left(\sigma_{t}\right)$ of the glasses was determined using the mass attenuation coefficient $\left(\mu_{\mathrm{m}}\right)$ via the following equation:

$$
\sigma_{t}=\frac{M \mu_{m}}{N_{A}}
$$


Where $M=\sum_{i} A_{i} n_{i}$ is the molecular weight of the sample, $A_{i}$ is the atomic weight of the $i$-th element, $n_{i}$ is the number of formula units of the molecule and $\mathrm{N}_{\mathrm{A}}$ is Avogadro's number.

The effective atomic cross section $\sigma_{\mathrm{a}}$ is calculated using the following equation:

$$
\sigma_{a}=\frac{\sigma_{t}}{\sum_{i} n_{i}}
$$

The total electronic cross section $\sigma_{\mathrm{e}}$ is calculated by:

$$
\sigma_{e}=\frac{1}{N_{A}} \sum_{i} \frac{f_{i} A_{i}}{Z_{i}}\left(\mu_{m}\right)_{i}
$$

where $f_{i}$ denotes the fractional abundance of element $I$, and $Z_{i}$ is the atomic number of the constituent element.

The effective atomic number $\left(\mathrm{Z}_{\mathrm{eff}}\right)$ is related to $\sigma_{\mathrm{a}}$ and $\sigma_{\mathrm{e}}$ by the following equation:

$$
Z_{e f f}=\frac{\sigma_{a}}{\sigma_{e}}
$$

The electron density (number of electrons per unit mass, $\left[\mathrm{N}_{\mathrm{el}}\right]$ ) of the sample can be calculated by the following equation:

$$
N_{e l}=\frac{Z_{\text {eff }} N_{A}}{M} \sum_{i} n_{i}\left(\frac{\text { electrons }}{g}\right)
$$

\subsection{Buildup Factors}

The logarithmic interpolation method for the equivalent atomic number $\left(Z_{\mathrm{eq}}\right)$ was used to calculate the exposure buildup factor values and the G-P fitting parameters of the tellurite glass samples. The computation method is illustrated step-by-step as follows:

1. Calculation of equivalent atomic number $\left(Z_{\mathrm{eq}}\right)$;

2. Calculation of the G-P fitting parameters; and

3. Calculation of the exposure buildup factors 
Since any single element has a fixed atomic number $Z$, a mixture, such as the zinc tellurite glasses studied here, will have an equivalent atomic number $\left(Z_{\text {eq }}\right)$, which describes the properties the of glass systems. Because the partial interaction of a gamma ray with a material depends on the energy, $Z_{\text {eq }}$ is an energy dependent parameter. Using the winXCom program, ${ }^{29,30}$ the total mass attenuation coefficient of selected $\mathrm{ZnO}-\mathrm{TeO}_{2}$ glasses and Compton partial mass attenuation coefficient for elements from $Z=4$ to $Z=50$ were obtained in the energy range of $0.015-15 \mathrm{MeV}$. The equivalent atomic number was calculated by matching the ratio of the Compton partial mass attenuation coefficient to the total mass attenuation coefficient of the selected glass systems with an identical ratio of a single element of the same energy. The following formula was used to interpolate the Zeq: ${ }^{31}$

$$
Z_{\text {eq }}=\frac{Z_{1}\left(\log R_{2}-\log R\right)+Z_{2}\left(\log R-\log R_{1}\right)}{\log R_{2}-\log R_{1}}
$$

where $Z_{1}$ and $Z_{2}$ are the atomic numbers of the elements corresponding to the ratios $R_{1}$ and $R_{2}$, respectively, and $R$ is the ratio of the glass sample at a specific energy. For example, the ratio $(\mu / \rho)_{\text {Compton }} /(\mu / \rho)_{\text {total }}$ of $10 \mathrm{ZnO}-90 \mathrm{TeO}_{2}$ at an energy of $0.3 \mathrm{MeV}$ is 0.635 , which lies between $\mathrm{R}_{1}=(\mu / \rho)_{\text {Compton }} /(\mu / \rho)_{\text {total }}=$ 0.628 of $\mathrm{Z}_{1}=46$ and $\mathrm{R}_{2}=(\mu / \rho)_{\text {Compton }} /(\mu / \rho)_{\text {total }}=0.645$ of $\mathrm{Z}=47$. Using Equation $7, Z_{\text {eq }}=46.42$ is calculated. The G-P fitting parameters are calculated using a similar logarithmic interpolation method to that used for $Z_{\mathrm{eq}}$. The G-P fitting parameters for the elements were taken from a report by the American Nuclear Society. ${ }^{19}$ The G-P fitting parameters for the glass samples were logarithmically interpolated using the same formula as follows: ${ }^{31}$

$$
C=\frac{C_{1}\left(\log Z_{2}-\log Z_{e q}\right)+C_{2}\left(\log Z_{e q}-\log Z_{1}\right)}{\log Z_{2}-\log Z_{1}}
$$

where $\mathrm{C}_{1}$ and $\mathrm{C}_{2}$ are the values of the G-P fitting parameters corresponding to the atomic numbers of $Z_{1}$ and $Z_{2}$, respectively, at a given energy. The G-P fitting parameters were used to calculate the exposure buildup factors of the glasses as follows: ${ }^{32}$

$$
\begin{array}{cc}
B(E, X)=1+\frac{b-1}{K-1}\left(K^{X}-1\right) & \text { for } K \neq 1 \\
B(K, X)=1+(b-1) X & \text { for } K=1
\end{array}
$$


where,

$K(E, x)=c x^{\alpha}+d \frac{\tan h\left(\frac{x}{X_{K}}-2\right)-\tan h(-2)}{1-\tan h(-2)} \quad$ for $x \leq 40 \mathrm{mfp}$

where $\mathrm{E}$ is the incident photon energy and $\mathrm{x}$ is the penetration depth in $\mathrm{mfp}$. Variables a through $\mathrm{d}$, along with $\mathrm{X}_{\mathrm{k}}$, are the G-P fitting parameters. The variation of the parameter $\mathrm{K}$ with the penetration depth represents the photon dose multiplication and a change in the shape of the spectrum.

\section{RESULTS AND DISCUSSION}

The density $(\rho)$ and the molar volume $\left(\mathrm{M}_{\mathrm{v}}\right)$ of the investigated glasises are listed in Table 1. It is observed that the density of the glass increased from $5.048-5.181\left(\mathrm{~g} \mathrm{~m}^{-3}\right)$ with the substitution of $\mathrm{TeO}_{2}$ by $\mathrm{ZnO}$, while the molar volume decreased from 30.067 to $24.766\left(\mathrm{~cm}^{3} \mathrm{~mol}^{-1}\right)$. The increase in density indicates that the zinc ions entered the tellurite glass network, which is related to the variation of the molar volume of the samples. The decrease in the molar volume is due to the decrease in the bond length, or inter-atomic spacing, between the atoms, which may be attributed to an increase in the stretching force constant (216-217.5 $\mathrm{N} \mathrm{m}^{-1}$ ) of the bonds inside the glass network. Hence, the radius of the $\mathrm{Zn}^{2+}(0.074 \mathrm{~nm})$ ions is much smaller than that of $\mathrm{Te}^{2+}(0.097 \mathrm{~nm})$, resulting in a more compact and dense glass. The addition of $\mathrm{ZnO}$ is probably caused by a change in the crosslink density and coordination number of the $\mathrm{Te}^{2+}$ ions. $^{31}$

\subsection{Mass Attenuation Coefficient $\left(\mu_{M}\right)$}

The experimental and theoretical values of the mass attenuation coefficients for the four glass samples at gamma energies of $0.662,1.173$ and $1.33 \mathrm{MeV}$ are given in Table 2. The theoretical values of the mass attenuation coefficients were calculated using WinXCom. ${ }^{28}$ The estimated error in the experimental measurements was $\leq 2 \%$. It is clear from Table 2 that the mass attenuation coefficients of the glass samples decreased with increasing gamma energy. At a low photon energy, the most important reaction between the studied glass samples and the gamma rays was the photoelectric effect, which decreases with increasing gamma energy. The behaviour of the mass attenuation coefficient at intermediate photon energies may be attributed to a Compton scattering process. The values of the mass attenuation coefficient are dependent on the elemental 
composition and, consequently, on the glass density. ${ }^{32}$ The experimental values $\left(\mu_{\mathrm{m}}\right)$ increased with increasing $\mathrm{ZnO}$ content. This behaviour may be attributed to the addition of $\mathrm{ZnO}$, which increases the glass density and decreases the molar volume, indicating that the glass structure becomes more compact and dense. The experimental mass attenuation coefficient values are in good agreement with the theoretical values.

Table 2: Theoretical $\left(\mu_{\mathrm{m}}\right)_{\mathrm{Xcom}}$ and experimental $\left(\mu_{\mathrm{m}}\right)_{\exp }$ mass attenuation coefficient of glass systems.

\begin{tabular}{ccccccc}
\hline \multirow{3}{*}{ Sample } & \multicolumn{2}{c}{$0.662 \mathrm{MeV}$} & \multicolumn{2}{c}{$1.173 \mathrm{MeV}$} & \multicolumn{2}{c}{$1.33 \mathrm{MeV}$} \\
\cline { 2 - 7 } & \multicolumn{5}{c}{$\mu_{\mathrm{m}} \times 10^{-2}\left(\mathrm{~cm}^{2} \mathrm{~g}^{-1}\right)$} \\
\cline { 2 - 7 } & WinXcom & Exp. & WinXcom & Exp. & WinXcom & Exp. \\
\hline 1 & 7.272 & $7.138 \pm$ & 5.322 & $5.216 \pm$ & 4.971 & $4.872 \pm$ \\
& & 0.134 & & 0.106 & & 0.099 \\
2 & 7.275 & $7.149 \pm$ & 5.347 & $5.239 \pm$ & 4.998 & $4.898 \pm$ \\
& & 0.126 & & 0.108 & & 0.100 \\
3 & 7.279 & $7.142 \pm$ & 5.386 & $5.277 \pm$ & 5.037 & $4.936 \pm$ \\
& & 0.137 & & 0.109 & & 0.101 \\
4 & 7.28 & $7.139 \pm$ & 5.399 & $5.305 \pm$ & 5.050 & $4.949 \pm$ \\
& & 0.141 & & 0.094 & & 0.101 \\
\hline
\end{tabular}

\subsection{HVL and MFP}

The half-value layer was calculated using the linear attenuation coefficient (in $\mathrm{cm}^{-1}$ ) as follows:

$$
H V L=\frac{\ln (2)}{\mu}
$$

Where $\mu\left(\mu=\rho \times \mu_{m}\right)$ is the linear attenuation coefficient, and the values of HVL are listed in Table 3. Figure 2 shows that the HVL values decreased with increasing values of $\mathrm{ZnO}$ in the glass systems at the photon energies of 0.662 , 1.173 and $1.33 \mathrm{MeV}$, which is due to an increase in the mass attenuation coefficient and density by replacing $\mathrm{TeO}_{2}$ with $\mathrm{ZnO}$. As shown in Figure 2, the half-value layer of the glass samples is lower than the corresponding values for barite and ferrite concretes at 0.662 and $1.33 \mathrm{MeV}$ photon energies. ${ }^{22}$ It has been observed that $\mathrm{ZnO}-\mathrm{TeO}_{2}$ class systems are better than concrete at absorbing gamma rays, indicating the potential for utilising the prepared glasses as radiation shields. 
Table 3: HVL and MFP of glass systems.

\begin{tabular}{ccccccc}
\hline \multirow{2}{*}{ Sample } & \multicolumn{3}{c}{ HVL $(\mathrm{cm})$} & \multicolumn{3}{c}{ MFP $(\mathrm{cm})$} \\
\cline { 2 - 7 } & $0.662 \mathrm{MeV}$ & $1.173 \mathrm{MeV}$ & $1.330 \mathrm{MeV}$ & $0.662 \mathrm{MeV}$ & $1.173 \mathrm{MeV}$ & $1.330 \mathrm{MeV}$ \\
\hline 1 & 1.893 & 2.590 & 2.773 & 2.73 & 3.74 & 4.00 \\
2 & 1.870 & 2.546 & 2.724 & 2.70 & 3.67 & 3.93 \\
3 & 1.852 & 2.509 & 2.684 & 2.67 & 3.62 & 3.87 \\
4 & 1.839 & 2.480 & 2.651 & 2.65 & 3.58 & 3.83 \\
\hline
\end{tabular}

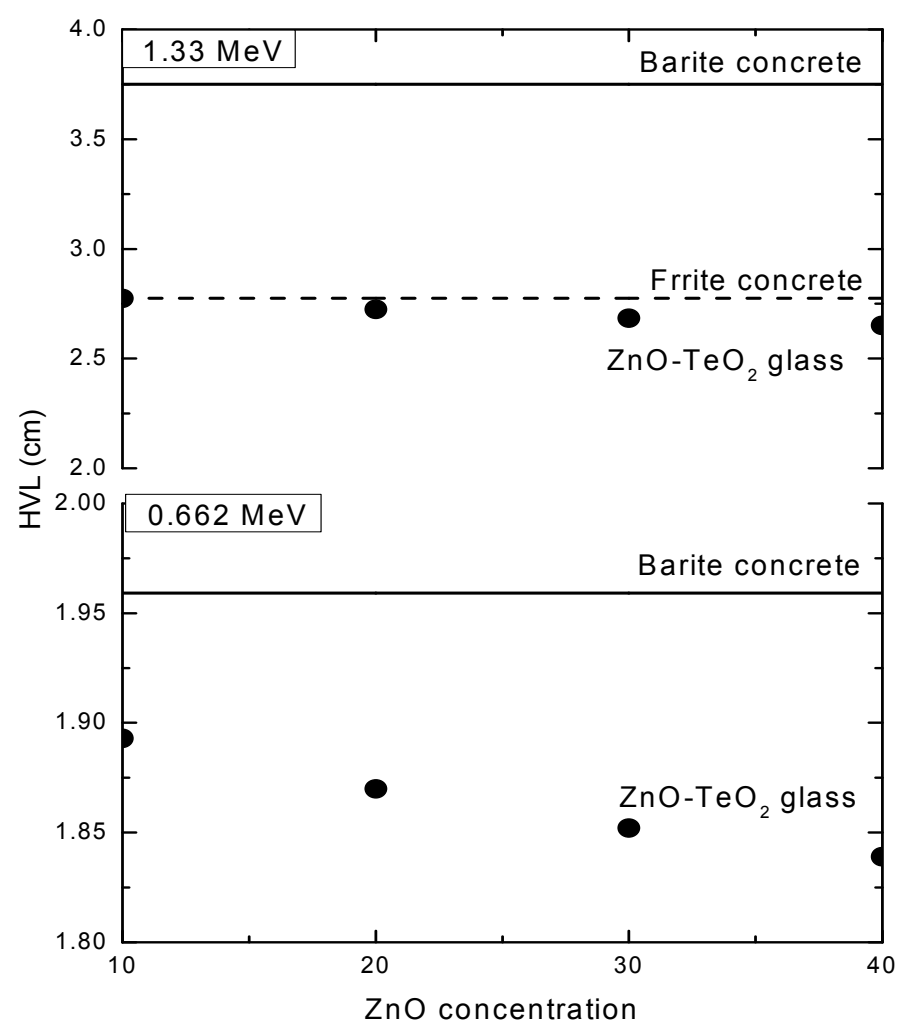

Figure 2: Variation of half value layer as a function of $\mathrm{ZnO}$ at 0.662 and $1.33 \mathrm{MeV}$ photon energy in the $(\bullet) \mathrm{ZnO}^{-\mathrm{TeO}_{2}}$ glass systems. Theoretical values at same energies for barite concrete and ferrite concrete.

The values of the mean free path (MFP) $\left(\mathrm{cm}^{-1}\right)$ of the prepared glass samples were obtained using the following equation: ${ }^{31}$

$$
M F P=\frac{1}{\mu}
$$


Table 3 shows that the values of the mean free path of the prepared glass samples decreased with increasing $\mathrm{ZnO}$ content. The MFP values of the $\mathrm{ZnO}-\mathrm{TeO}_{2}$ glasses were compared with some standard radiation shielding concretes ${ }^{33}$ (Figure 3). Figure 3 shows that the values of the mean free path are lower than those in ilmenite, basalt-magnetite, haematite-serpentine and ordinary concretes at $0.662,1.173$, and $1.33 \mathrm{MeV}$ photon energies. This result indicates that the glass samples are better radiation shielding materials compared with standard shielding concretes. A material to be used as a gamma ray radiation shielding material must have low values of HVL and MFP. Therefore, the results indicated that $\mathrm{ZnO}-\mathrm{TeO}_{2}$ glass systems, which show lower values of HVL and MFP at photon energy $0.662,1.173$ and $1.33 \mathrm{MeV}$, are better for gamma ray shielding. Hence, it is thought that the prepared glass samples can be promising candidates for non-conventional alternatives for gamma ray shielding applications.

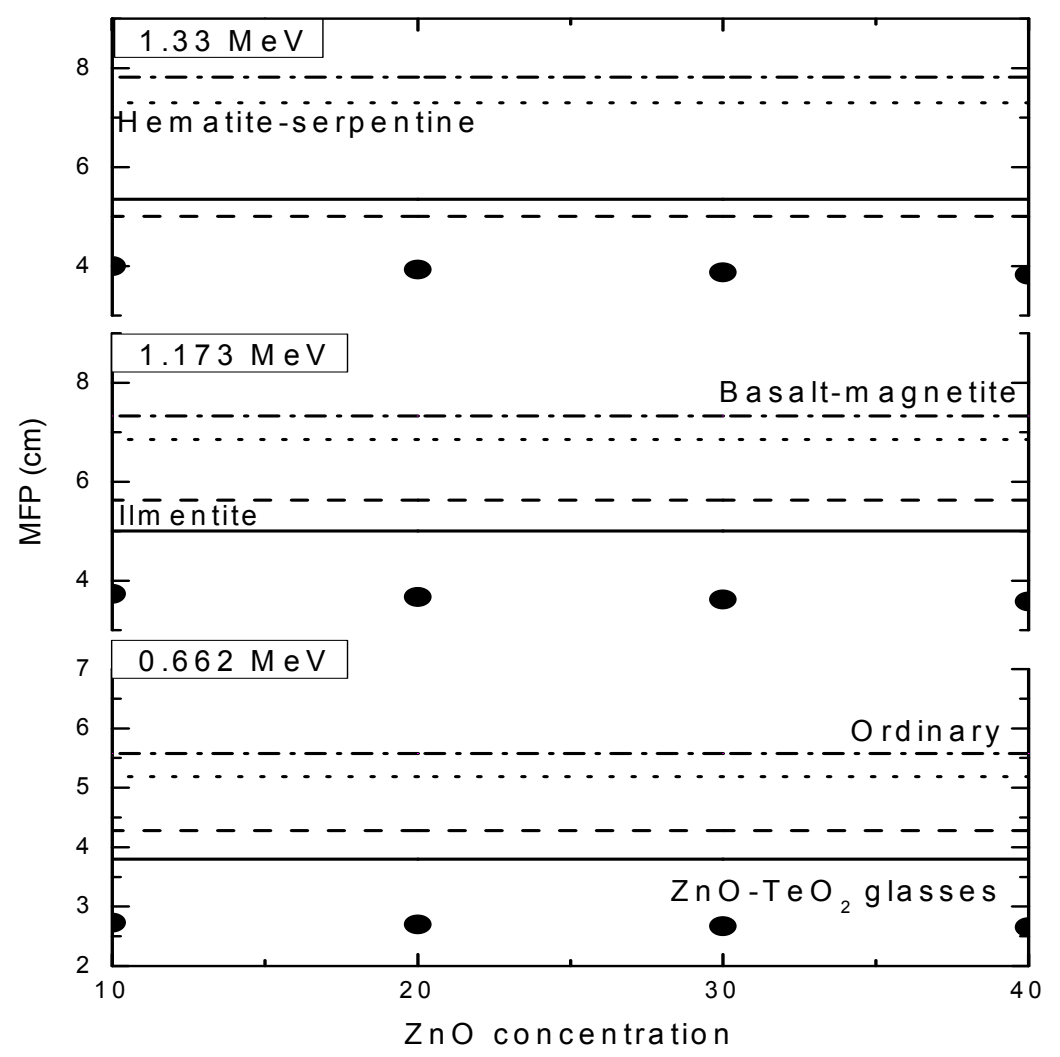

Figure 3: Variation of mean free path as a function of $\mathrm{ZnO}$ oxide at $0.662,1.173$ and $1.33 \mathrm{MeV}$ photon energy in the $(\bullet) \mathrm{ZnO}^{-} \mathrm{TeO}_{2}$ glass systems. Theoretical values at same energies for ordinary concrete, hematite-serpentine, basaltmagnetite and ilmentite. 


\subsection{Effective Atomic Number $\left(\mathrm{Z}_{\mathrm{eff}}\right)$ and Electron Density $\left(\mathrm{N}_{\mathrm{el}}\right)$}

The effective atomic number $\left(\mathrm{Z}_{\mathrm{eff}}\right)$ and electron density $\left(\mathrm{N}_{\mathrm{el}}\right)$ of the glass samples in the energy range of $0.015-15 \mathrm{MeV}$ are presented in Table 4. Equations 5 and 6 have been used, respectively, to calculate the effective atomic number $\left(Z_{\text {eff }}\right)$ and electron density $\left(\mathrm{N}_{\mathrm{el}}\right)$. The variation of $\mathrm{Z}_{\mathrm{eff}}$ with photon energy for all interaction processes in the glasses is shown in Figure 4. It can be observed that initially, the photoelectric interaction dominates and the effective atomic number remains almost constant in the energy range of $0.015-0.03 \mathrm{MeV}$. Then, it starts increasing and reaches a maximum at $0.04 \mathrm{MeV}$. Finally, it decreases sharply with increasing energy up to $1 \mathrm{MeV}$, which indicates that the Compton scattering process begins to occur. In the intermediate energy region $(0.6-2 \mathrm{MeV})$, the $Z_{\text {eff }}$ values have been found to be almost constant for the selected materials, which clearly indicates that the Compton scattering cross section depends only on the energy and is almost independent of the composition of the materials. Finally, the effective atomic number increased with increasing photon energy. This is due to the domination of the pair production process, whose cross section is proportional with $Z^{2}$. Figure 4 shows that in the photon energy range $0.04-0.6 \mathrm{MeV}$, the $10 \mathrm{ZnO}-90 \mathrm{TeO}_{2}$ glass sample has the highest effective atomic number. The variation of electron density when investigating glass systems with photons in the range of $0.015-15 \mathrm{MeV}$ have demonstrated the same behaviour of $Z_{\text {eff }}$ as shown in Figure 5.

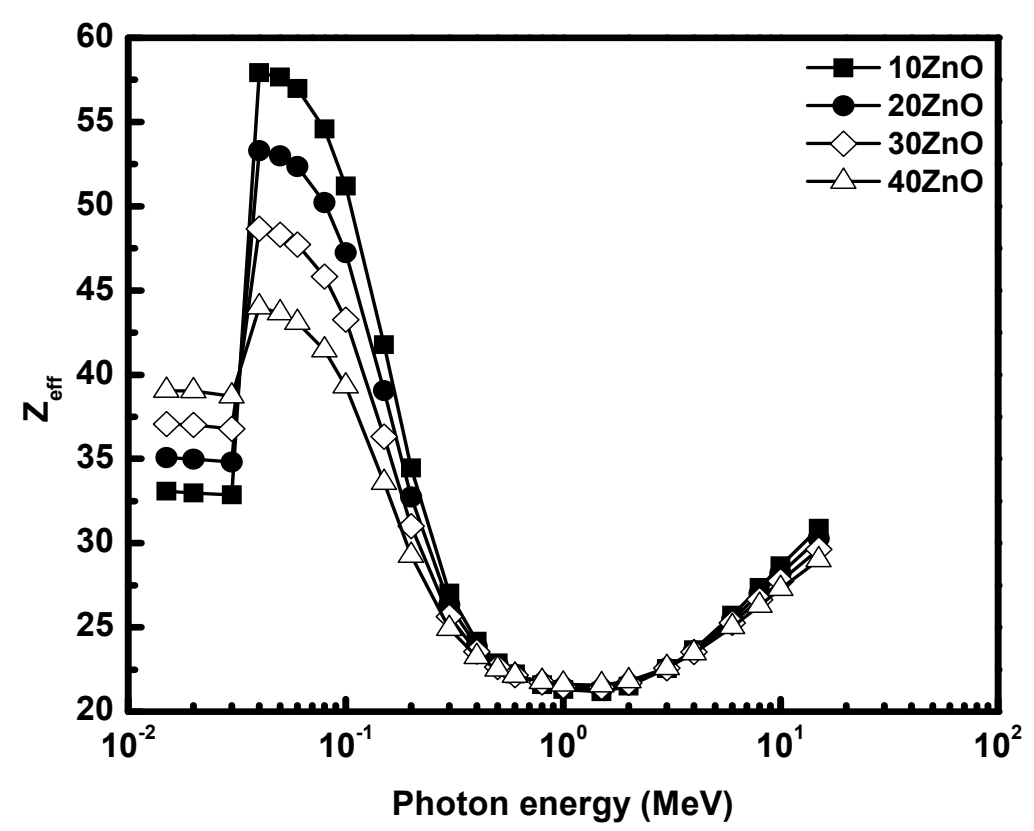

Figure 4: The variation of $Z_{\text {eff }}$ with photon energy of glass samples. 
Table 4: Effective atomic number $\left(\mathrm{Z}_{\mathrm{eff}}\right)$ and electron density $\left(\mathrm{N}_{\mathrm{el}}\right) \times 10^{23}$ of glass samples.

\begin{tabular}{ccccccccc}
\hline \multirow{2}{*}{ Energy $(\mathrm{MeV})$} & \multicolumn{2}{c}{$10 \mathrm{ZnO}$} & \multicolumn{2}{c}{$20 \mathrm{ZnO}$} & \multicolumn{2}{c}{$30 \mathrm{ZnO}$} & \multicolumn{2}{c}{$40 \mathrm{ZnO}$} \\
\cline { 2 - 9 } $\mathrm{Z}_{\text {eff }}$ & $\mathrm{N}_{\mathrm{el}}$ & $\mathrm{Z}_{\text {eff }}$ & $\mathrm{N}_{\mathrm{el}}$ & $\mathrm{Z}_{\text {eff }}$ & $\mathrm{N}_{\mathrm{el}}$ & $\mathrm{Z}_{\text {eff }}$ & $\mathrm{N}_{\mathrm{el}}$ \\
\hline 0.015 & 33.087 & 4.134 & 35.074 & 4.382 & 37.062 & 4.631 & 39.050 & 4.879 \\
0.02 & 32.977 & 4.120 & 34.995 & 4.372 & 37.012 & 4.624 & 39.029 & 4.876 \\
0.03 & 32.859 & 4.106 & 34.816 & 4.350 & 36.773 & 4.595 & 38.730 & 4.839 \\
0.04 & 57.927 & 7.238 & 53.289 & 6.658 & 48.652 & 6.079 & 44.014 & 5.499 \\
0.05 & 57.667 & 7.205 & 52.995 & 6.621 & 48.322 & 6.038 & 43.650 & 5.454 \\
0.06 & 56.989 & 7.120 & 52.355 & 6.541 & 47.722 & 5.963 & 43.089 & 5.384 \\
0.08 & 54.585 & 6.820 & 50.205 & 6.273 & 45.826 & 5.726 & 41.447 & 5.179 \\
0.1 & 51.195 & 6.397 & 47.233 & 5.901 & 43.270 & 5.406 & 39.308 & 4.911 \\
0.15 & 41.771 & 5.219 & 39.046 & 4.879 & 36.320 & 4.538 & 33.594 & 4.197 \\
0.2 & 34.468 & 4.307 & 32.734 & 4.090 & 31.001 & 3.873 & 29.268 & 3.657 \\
0.3 & 27.043 & 3.379 & 26.336 & 3.291 & 25.629 & 3.202 & 24.923 & 3.114 \\
0.4 & 24.179 & 3.021 & 23.873 & 2.983 & 23.567 & 2.945 & 23.261 & 2.906 \\
0.5 & 22.891 & 2.860 & 22.767 & 2.845 & 22.643 & 2.829 & 22.520 & 2.814 \\
0.6 & 22.229 & 2.777 & 22.200 & 2.774 & 22.170 & 2.770 & 22.141 & 2.766 \\
0.8 & 21.596 & 2.698 & 21.657 & 2.706 & 21.718 & 2.714 & 21.779 & 2.721 \\
1 & 21.310 & 2.663 & 21.412 & 2.675 & 21.514 & 2.688 & 21.616 & 2.701 \\
1.5 & 21.185 & 2.647 & 21.312 & 2.663 & 21.439 & 2.679 & 21.566 & 2.695 \\
2 & 21.505 & 2.687 & 21.608 & 2.700 & 21.710 & 2.713 & 21.813 & 2.725 \\
3 & 22.548 & 2.817 & 22.567 & 2.820 & 22.585 & 2.822 & 22.604 & 2.824 \\
4 & 23.681 & 2.959 & 23.609 & 2.950 & 23.537 & 2.941 & 23.465 & 2.932 \\
5 & 25.720 & 3.214 & 25.491 & 3.185 & 25.262 & 3.156 & 25.033 & 3.128 \\
6 & 27.353 & 3.418 & 27.001 & 3.374 & 26.649 & 3.330 & 26.297 & 3.286 \\
8 & 28.649 & 3.579 & 28.198 & 3.523 & 27.747 & 3.467 & 27.297 & 3.411 \\
10 & 30.887 & 3.859 & 30.259 & 3.781 & 29.632 & 3.702 & 29.004 & 3.624 \\
15 & 33.087 & 4.134 & 35.074 & 4.382 & 37.062 & 4.631 & 39.050 & 4.879 \\
\hline & & & & & & & &
\end{tabular}




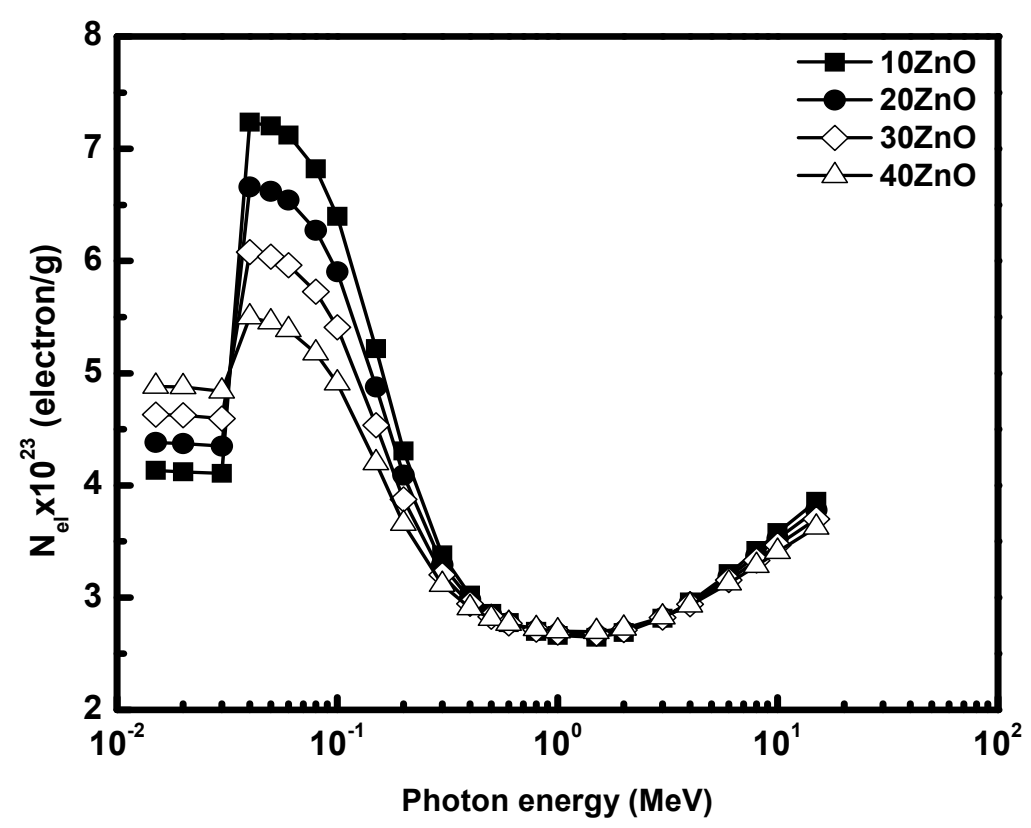

Figure 5: The variation of $\mathrm{N}_{\mathrm{el}}$ with photon energy of glass samples.

\subsection{Gamma Ray Buildup Factors of the Glass Samples}

\subsubsection{Photon energy dependence}

The calculated equivalent atomic numbers $\left(\mathrm{Z}_{\mathrm{eq}}\right)$ and EBF G-P fitting parameters for the glass samples in the energy range of $0.015-15 \mathrm{MeV}$ are shown in Tables 5-8. Figure 6 shows the variation in the exposure buildup factor with photon energy for the glass samples at different penetration depths. It is observed that the exposure (EBF) buildup factors of the glass samples are small at both low and high energies. This may be attributed to the absorption processes, photoelectric effect and pair-production dominating at the low and high energy regions, respectively, in which photons are completely absorbed or removed. A sharp peak in the EBF values was observed at $40 \mathrm{keV}$ as shown in Figure 6, which may be due to the $\mathrm{K}$-absorption edge of Te at approximately $31.8 \mathrm{keV}$. Around the $\mathrm{K}$-edge of high- $\mathrm{Z}$ elements, the mass attenuation coefficients jump to very large values at the upper side of the K-edge, and the element exhibits two mass attenuation coefficients, corresponding to the lower and upper sides of the edge. This abrupt change in the mass attenuation coefficient could lead a sharp peak in the buildup factor. The EBF values increase with increasing photon energies and show a maximum at $0.8 \mathrm{MeV}$ due to multiple Compton scattering at intermediate energies. In Compton scattering, photons are not completely removed, but rather they lose energy. Finally, the EBF values begin to decrease upon further 
increases in the photon energy up to $8 \mathrm{MeV}$ due to pair production. We found that EBF values increased at a high energy $(>8 \mathrm{MeV})$ for all of the glass samples and showed increasing penetration depths, which might be due to the increase in multiple scattering as the penetration depth increased. The EBF values were found to be in the range of 1.005-4180.6, 1.004-2730.3, 1.004-1741.2 and $1.004-1073.1$ for the $10 \mathrm{ZnO}, 20 \mathrm{ZnO}, 30 \mathrm{ZnO}$, and $40 \mathrm{ZnO}$ glass samples, respectively. The dependence on the chemical composition agreed with what was observed elsewhere. ${ }^{34}$

Table 5: Equivalent atomic number $\left(\mathrm{Z}_{\mathrm{eq}}\right)$ and G-P exposure (EBF) buildup factor coefficients for $10 \mathrm{ZnO}-90 \mathrm{TeO}_{2}$ glass sample.

\begin{tabular}{|c|c|c|c|c|c|c|}
\hline \multirow{2}{*}{ Energy $(\mathrm{MeV})$} & \multirow{2}{*}{$\mathrm{Z}_{\mathrm{eq}}$} & \multicolumn{5}{|c|}{ EBF } \\
\hline & & $\mathrm{b}$ & $\mathrm{c}$ & $\mathrm{a}$ & $X_{k}$ & $\mathrm{~d}$ \\
\hline 0.015 & 24.78 & 1.005 & 1.385 & -0.449 & 5.861 & 0.312 \\
\hline 0.02 & 24.89 & 1.013 & 0.182 & 0.547 & 11.307 & -0.528 \\
\hline 0.03 & 25.12 & 1.032 & 0.374 & 0.195 & 26.998 & -0.291 \\
\hline 0.04 & 44.48 & 3.820 & 0.618 & 0.091 & 24.341 & -0.063 \\
\hline 0.05 & 44.90 & 3.254 & 0.212 & -0.088 & 13.814 & -0.056 \\
\hline 0.06 & 45.19 & 2.634 & 0.101 & 0.628 & 12.258 & -0.109 \\
\hline 0.08 & 45.57 & 1.730 & 0.026 & 0.788 & 14.892 & -0.208 \\
\hline 0.1 & 45.81 & 1.276 & 0.179 & 0.488 & 13.770 & -0.238 \\
\hline 0.15 & 46.16 & 1.229 & 0.401 & 0.231 & 14.165 & -0.126 \\
\hline 0.2 & 46.35 & 1.353 & 0.506 & 0.172 & 14.477 & -0.095 \\
\hline 0.3 & 46.58 & 1.480 & 0.682 & 0.095 & 14.336 & -0.047 \\
\hline 0.4 & 46.70 & 1.601 & 0.828 & 0.054 & 14.156 & -0.039 \\
\hline 0.5 & 46.78 & 1.672 & 0.912 & 0.033 & 14.163 & -0.031 \\
\hline 0.6 & 46.84 & 1.702 & 0.968 & 0.017 & 13.990 & -0.022 \\
\hline 0.8 & 46.88 & 1.728 & 1.026 & 0.002 & 14.064 & -0.016 \\
\hline 1 & 46.90 & 1.721 & 1.052 & -0.004 & 13.430 & -0.014 \\
\hline 1.5 & 46.12 & 1.595 & 1.140 & -0.025 & 10.981 & -0.002 \\
\hline 2 & 44.16 & 1.588 & 1.122 & -0.020 & 12.758 & -0.006 \\
\hline 3 & 41.70 & 1.558 & 1.065 & 0.000 & 12.828 & -0.028 \\
\hline 4 & 40.76 & 1.508 & 1.023 & 0.015 & 13.324 & -0.041 \\
\hline 5 & 40.25 & 1.514 & 0.950 & 0.042 & 13.552 & -0.066 \\
\hline 6 & 39.90 & 1.487 & 0.931 & 0.052 & 13.738 & -0.074 \\
\hline 8 & 39.49 & 1.501 & 0.892 & 0.073 & 14.042 & -0.091 \\
\hline 10 & 39.28 & 1.464 & 0.964 & 0.056 & 14.156 & -0.075 \\
\hline 15 & 39.18 & 1.501 & 1.090 & 0.038 & 14.220 & -0.061 \\
\hline
\end{tabular}


Table 6: Equivalent atomic number $\left(\mathrm{Z}_{\mathrm{eq}}\right)$ and G-P exposure (EBF) buildup factor coefficients for $20 \mathrm{ZnO}-80 \mathrm{TeO}_{2}$ glass sample.

\begin{tabular}{|c|c|c|c|c|c|c|}
\hline \multirow{2}{*}{ Energy $(\mathrm{MeV})$} & \multirow{2}{*}{$\mathrm{Z}_{\mathrm{eq}}$} & \multicolumn{5}{|c|}{ EBF } \\
\hline & & $\mathrm{b}$ & $\mathrm{c}$ & $\mathrm{a}$ & $\mathrm{X}_{\mathrm{k}}$ & $\mathrm{d}$ \\
\hline 0.015 & 25.11 & 1.004 & 1.432 & -0.477 & 5.791 & 0.323 \\
\hline 0.02 & 25.22 & 1.012 & 0.166 & 0.569 & 11.332 & -0.555 \\
\hline 0.03 & 25.44 & 1.030 & 0.374 & 0.193 & 27.873 & -0.301 \\
\hline 0.04 & 42.90 & 3.896 & 0.431 & 0.089 & 23.728 & -0.043 \\
\hline 0.05 & 43.34 & 3.177 & 0.120 & -0.209 & 12.835 & 0.003 \\
\hline 0.06 & 43.66 & 2.528 & 0.055 & 0.851 & 14.732 & -0.127 \\
\hline 0.08 & 44.05 & 1.701 & 0.029 & 0.779 & 14.687 & -0.228 \\
\hline 0.1 & 44.31 & 1.231 & 0.225 & 0.412 & 13.762 & -0.207 \\
\hline 0.15 & 44.70 & 1.233 & 0.431 & 0.211 & 14.252 & -0.113 \\
\hline 0.2 & 44.91 & 1.392 & 0.509 & 0.172 & 14.417 & -0.096 \\
\hline 0.3 & 45.17 & 1.512 & 0.697 & 0.091 & 14.382 & -0.046 \\
\hline 0.4 & 45.31 & 1.633 & 0.846 & 0.050 & 14.163 & -0.037 \\
\hline 0.5 & 45.39 & 1.700 & 0.930 & 0.028 & 14.210 & -0.029 \\
\hline 0.6 & 45.44 & 1.728 & 0.984 & 0.013 & 13.976 & -0.021 \\
\hline 0.8 & 45.49 & 1.749 & 1.039 & -0.001 & 14.052 & -0.015 \\
\hline 1 & 45.52 & 1.738 & 1.063 & -0.007 & 13.430 & -0.013 \\
\hline 1.5 & 44.64 & 1.605 & 1.147 & -0.027 & 9.640 & -0.001 \\
\hline 2 & 42.47 & 1.598 & 1.126 & -0.021 & 12.651 & -0.006 \\
\hline 3 & 39.95 & 1.565 & 1.064 & -0.001 & 12.755 & -0.026 \\
\hline 4 & 39.00 & 1.513 & 1.023 & 0.015 & 13.272 & -0.039 \\
\hline 5 & 38.50 & 1.510 & 0.958 & 0.039 & 13.512 & -0.061 \\
\hline 6 & 38.17 & 1.479 & 0.940 & 0.048 & 13.668 & -0.069 \\
\hline 8 & 37.77 & 1.480 & 0.901 & 0.068 & 13.964 & -0.086 \\
\hline 10 & 37.57 & 1.438 & 0.964 & 0.054 & 14.120 & -0.072 \\
\hline 15 & 37.47 & 1.455 & 1.072 & 0.040 & 14.259 & -0.061 \\
\hline
\end{tabular}


Table 7: Equivalent atomic number $\left(\mathrm{Z}_{\mathrm{eq}}\right)$ and G-P exposure (EBF) buildup factor coefficients for $30 \mathrm{ZnO}-70 \mathrm{TeO}_{2}$ glass sample.

\begin{tabular}{|c|c|c|c|c|c|c|}
\hline \multirow{2}{*}{ Energy $(\mathrm{MeV})$} & \multirow{2}{*}{$\mathrm{Z}_{\mathrm{eq}}$} & \multicolumn{5}{|c|}{ EBF } \\
\hline & & $\mathrm{b}$ & $\mathrm{c}$ & $\mathrm{a}$ & $X_{k}$ & $\mathrm{~d}$ \\
\hline 0.015 & 25.41 & 1.004 & 1.477 & -0.504 & 5.725 & 0.333 \\
\hline 0.02 & 25.53 & 1.012 & 0.152 & 0.590 & 11.355 & -0.579 \\
\hline 0.03 & 25.74 & 1.029 & 0.374 & 0.191 & 28.675 & -0.310 \\
\hline 0.04 & 41.31 & 3.811 & 0.322 & 0.095 & 22.971 & -0.035 \\
\hline 0.05 & 41.75 & 3.077 & 0.043 & -0.308 & 11.975 & 0.053 \\
\hline 0.06 & 42.08 & 2.414 & 0.007 & 1.091 & 17.382 & -0.147 \\
\hline 0.08 & 42.49 & 1.671 & 0.032 & 0.770 & 14.470 & -0.249 \\
\hline 0.1 & 42.77 & 1.183 & 0.275 & 0.331 & 13.754 & -0.173 \\
\hline 0.15 & 43.17 & 1.238 & 0.464 & 0.191 & 14.346 & -0.100 \\
\hline 0.2 & 43.38 & 1.434 & 0.511 & 0.173 & 14.352 & -0.098 \\
\hline 0.3 & 43.67 & 1.548 & 0.714 & 0.086 & 14.432 & -0.044 \\
\hline 0.4 & 43.81 & 1.667 & 0.866 & 0.045 & 14.170 & -0.036 \\
\hline 0.5 & 43.93 & 1.731 & 0.951 & 0.023 & 14.261 & -0.027 \\
\hline 0.6 & 43.97 & 1.756 & 1.000 & 0.009 & 13.961 & -0.020 \\
\hline 0.8 & 44.04 & 1.771 & 1.053 & -0.004 & 14.039 & -0.014 \\
\hline 1 & 44.02 & 1.757 & 1.075 & -0.009 & 13.430 & -0.012 \\
\hline 1.5 & 42.93 & 1.616 & 1.155 & -0.029 & 8.171 & 0.000 \\
\hline 2 & 40.79 & 1.609 & 1.127 & -0.021 & 12.312 & -0.005 \\
\hline 3 & 38.19 & 1.572 & 1.063 & -0.001 & 12.678 & -0.025 \\
\hline 4 & 37.27 & 1.518 & 1.023 & 0.014 & 13.218 & -0.037 \\
\hline 5 & 36.44 & 1.505 & 0.966 & 0.035 & 13.472 & -0.056 \\
\hline 6 & 36.44 & 1.471 & 0.949 & 0.043 & 13.595 & -0.063 \\
\hline 8 & 36.12 & 1.458 & 0.912 & 0.063 & 13.884 & -0.081 \\
\hline 10 & 35.89 & 1.411 & 0.964 & 0.052 & 14.082 & -0.070 \\
\hline 15 & 35.80 & 1.408 & 1.054 & 0.042 & 14.298 & -0.062 \\
\hline
\end{tabular}


Table 8: Equivalent atomic number $\left(\mathrm{Z}_{\mathrm{eq}}\right)$ and G-P exposure (EBF) buildup factor coefficients for $40 \mathrm{ZnO}-60 \mathrm{TeO}_{2}$ glass sample.

\begin{tabular}{|c|c|c|c|c|c|c|}
\hline \multirow{2}{*}{ Energy $(\mathrm{MeV})$} & \multirow{2}{*}{$\mathrm{Z}_{\mathrm{eq}}$} & \multicolumn{5}{|c|}{ EBF } \\
\hline & & $\mathrm{b}$ & $\mathrm{c}$ & $\mathrm{a}$ & $\mathrm{X}_{\mathrm{k}}$ & $\mathrm{d}$ \\
\hline 0.015 & 25.70 & 1.004 & 1.518 & -0.528 & 5.664 & 0.342 \\
\hline 0.02 & 25.82 & 1.012 & 0.138 & 0.608 & 11.377 & -0.602 \\
\hline 0.03 & 26.03 & 1.020 & 0.374 & 0.190 & 29.160 & -0.314 \\
\hline 0.04 & 39.66 & 3.492 & 0.323 & 0.111 & 21.988 & -0.042 \\
\hline 0.05 & 40.11 & 2.856 & 0.077 & -0.248 & 12.075 & 0.031 \\
\hline 0.06 & 40.44 & 2.275 & 0.041 & 1.015 & 17.114 & -0.147 \\
\hline 0.08 & 40.85 & 1.626 & 0.064 & 0.724 & 14.368 & -0.245 \\
\hline 0.1 & 41.13 & 1.165 & 0.312 & 0.283 & 13.758 & -0.152 \\
\hline 0.15 & 41.55 & 1.249 & 0.495 & 0.172 & 14.407 & -0.089 \\
\hline 0.2 & 41.79 & 1.477 & 0.518 & 0.171 & 14.281 & -0.098 \\
\hline 0.3 & 42.08 & 1.587 & 0.732 & 0.080 & 14.487 & -0.043 \\
\hline 0.4 & 42.24 & 1.705 & 0.888 & 0.039 & 14.179 & -0.034 \\
\hline 0.5 & 42.34 & 1.766 & 0.973 & 0.017 & 14.318 & -0.024 \\
\hline 0.6 & 42.40 & 1.788 & 1.019 & 0.005 & 13.944 & -0.019 \\
\hline 0.8 & 42.47 & 1.796 & 1.068 & -0.007 & 14.024 & -0.013 \\
\hline 1 & 42.49 & 1.777 & 1.088 & -0.012 & 13.430 & -0.011 \\
\hline 1.5 & 41.41 & 1.628 & 1.162 & -0.030 & 7.557 & 0.001 \\
\hline 2 & 38.94 & 1.620 & 1.126 & -0.021 & 11.860 & -0.005 \\
\hline 3 & 36.42 & 1.580 & 1.063 & -0.002 & 12.597 & -0.023 \\
\hline 4 & 35.53 & 1.524 & 1.023 & 0.013 & 13.161 & -0.035 \\
\hline 5 & 35.08 & 1.500 & 0.974 & 0.031 & 13.429 & -0.051 \\
\hline 6 & 34.78 & 1.462 & 0.959 & 0.039 & 13.519 & -0.058 \\
\hline 8 & 34.44 & 1.436 & 0.922 & 0.058 & 13.802 & -0.075 \\
\hline 10 & 34.26 & 1.385 & 0.963 & 0.050 & 14.045 & -0.067 \\
\hline 15 & 34.17 & 1.360 & 1.035 & 0.044 & 14.338 & -0.062 \\
\hline
\end{tabular}



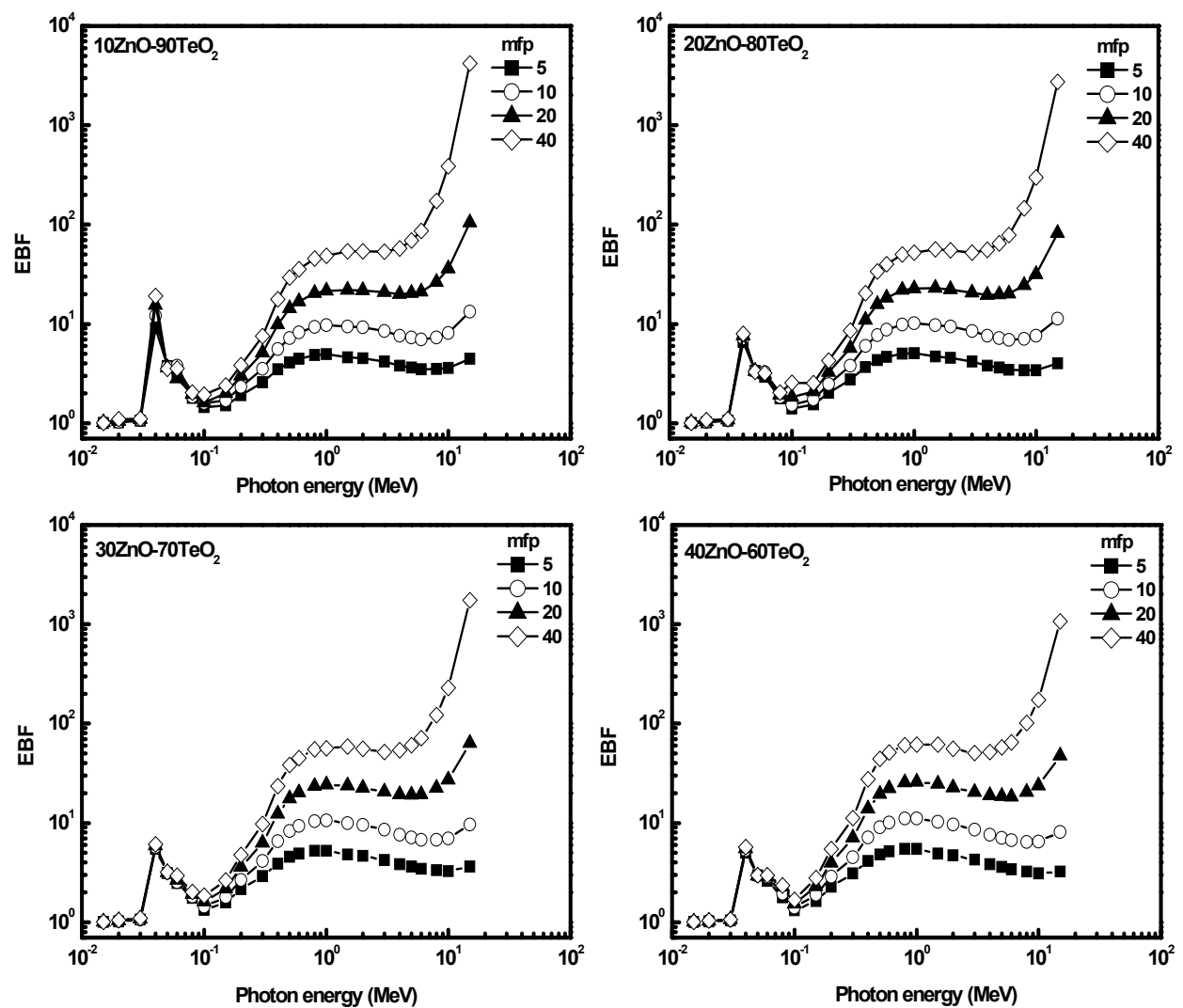

Figure 6: The exposure buildup factor (EBF) for the glass samples in the energy region $0.015-15 \mathrm{MeV}$ at different penetration depth.

\subsubsection{Penetration depth dependency}

Figure 7 shows the variation of the EBF with penetration depth for four incident photon energies $(0.015,0.15,1.5$, and $15 \mathrm{MeV})$. It is clear that the of EBF values increased with increasing penetration depth for the glass samples. At low penetration depths, up to $3 \mathrm{mfp}$ and $0.15 \mathrm{MeV}$ incident photon energy, the EBF values remained constant with increasing $\mathrm{ZnO}$ content. At a photon energy of 1.5 $\mathrm{MeV}$, the EBF values remained constant with increasing $\mathrm{ZnO}$ content and penetration depths up to $20 \mathrm{mfp}$. This may be due to the domination of photoelectric absorption, which depends on $Z_{e q}^{4-5}$ at photon energies below 0.15 $\mathrm{MeV}$. In the high photon energy region $(>2 \mathrm{MeV})$, another absorption process, pair and triplet production, overwhelms the Compton scattering. 

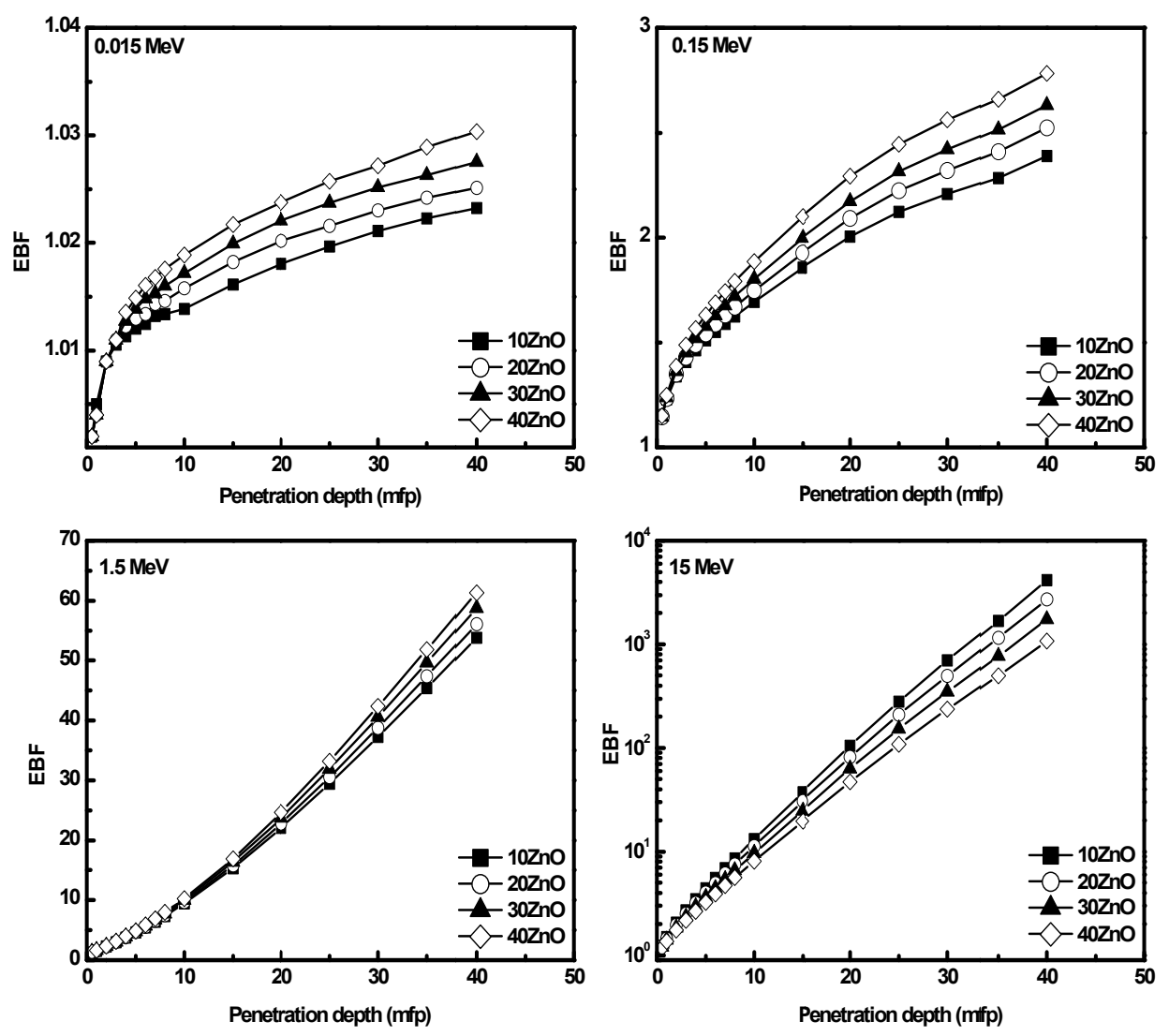

Figure 7: The exposure buildup factor for the glass samples up to $40 \mathrm{mfp}$ at $0.015,0.15$, $1.5,15 \mathrm{MeV}$.

\section{CONCLUSION}

The mass attenuation coefficient $\left(\mu_{\mathrm{m}}\right)$, half-value layer (HVL) and mean free path for $x \mathrm{ZnO}-(100-x) \mathrm{TeO}_{2}$ glasses, where $x=10,20,30$ and $40 \mathrm{~mol} \%$, have been measured for $0.662,1.173$ and $1.33 \mathrm{MeV}$ emitted from ${ }^{137} \mathrm{Cs}$ and ${ }^{60} \mathrm{Coby}$ using a $3 \times 3$ inch $\mathrm{NaI}(\mathrm{Tl})$ detector. The experimental mass attenuation coefficients were found to decrease with increasing gamma ray energy and increase with increasing $\mathrm{ZnO}$ concentration. The half-value layer and mean free path at selected photon energies increased with increasing gamma energy and decreased with increasing $\mathrm{ZnO}$ concentration. The results show that the values of the mean free path of glass samples are lower than those of ilmenite, basalt-magnetite, haematiteserpentine, and ordinary concretes at photon energies of $0.662,1.173$, and 1.33 $\mathrm{MeV}$. The effective atomic numbers $\left(\mathrm{Z}_{\mathrm{eff}}\right)$ and electron densities $\left(\mathrm{N}_{\mathrm{el}}\right)$ of the glass 
samples were calculated in the photon energy range of $0.015-15 \mathrm{MeV}$ and were found to be clearly energy dependent. The G-P fitting method has been used for the calculation of the exposure and buildup factors of the glass samples in the energy range $0.015-15 \mathrm{MeV}$ up to 40 penetration depths. The $10 \mathrm{ZnO}-90 \mathrm{TeO}_{2}$ glass sample was found to have lower values of the gamma ray exposure buildup factor in the intermediate energy region. The EBF was found to be energy and penetration depth dependent as well.

\section{ACKNOWLEDGEMENT}

This work was carried out using the analytical facilities at the Physics Department, Faculty of Sciences, Al-Azhar University, Assiut, Egypt and Physics Department, Faculty of Science, University of Tabuk, Saudi Arabia.

\section{REFERENCES}

1. Kaur, K., Singh, K. J. \& Anand, V. (2015). Correlation of gamma ray shielding and structural properties of $\mathrm{PbO}-\mathrm{BaO}-\mathrm{P}_{2} \mathrm{O}_{5}$ glass system. Nucl. Eng. Des., 285, 31-38, http://dx.doi.org/10.1016/j.nucengdes.2014. 12.033 .

2. Saeed, A. et al. (2014). Gamma ray attenuation in a developed borate glassy system. Radiat. Phys. Chem., 102, 167-170, http://dx.doi.org/ 10.1016/j.radphyschem.2014.04.032.

3. Singh, K. J., Kaur, S. \& Kaundal, R. S. (2014). Comparative study of gamma ray shielding and some properties of $\mathrm{PbO}-\mathrm{SiO}_{2}-\mathrm{Al}_{2} \mathrm{O}_{3}$ and $\mathrm{Bi}_{2} \mathrm{O}_{3}-$ $\mathrm{SiO}_{2}-\mathrm{Al}_{2} \mathrm{O}_{3}$ glass systems. Radiat. Phys. Chem., 96, 153-157, http://dx.doi.org/10.1016/j.radphyschem.2013.09.015.

4. Singh, V. P. et al. (2014). Evaluation of gamma-ray exposure buildup factors and neutron shielding for bismuth borosilicate glasses. Radiat. Phys. Chem., 98, 14-21, http://dx.doi.org/10.1016/j.radphysschem.2013. 12.029 .

5. Wang, J., Vogel, E. \& Snitzer, E. (1994). Tellurite glass: A new candidate for fiber devices. Opt. Mater., 3, 187-203, http://dx.doi.org/ 10.1016/0925-3467(94)90004-3.

6. Ulrich, D. R. (1964). Electrical and infrared properties of glasses in the system $\mathrm{Bi}_{2} \mathrm{O}_{3}-\mathrm{TeO}_{2}$. J. Am. Ceram. Soc., 47, 595-596, http://dx.doi.org/ 10.1111/j.1151-2916.1964.tb13828.x.

7. Burger, H. et al. (1992). Glass formation, properties and structure of glasses in the $\mathrm{TeO}_{2}-\mathrm{ZnO}$ system. J. Non-Cryst. Solids, 151, 134-142. 
8. Murugan, G. S. et al. (2004). Second-harmonic generation in transparent surface crystallized glasses in the $\mathrm{BaO}-\mathrm{B}_{2}-\mathrm{O}_{3}-\mathrm{TeO}_{2}$ system. Appl. Phys. Lett., 85, 3405, http://dx.doi.org/10.1063/1.1808873.

9. Manikandan, N., Ryasnyanskiy, A. \& Toulouse, J. (2012). Thermal and optical properties of $\mathrm{TeO}_{2}-\mathrm{ZnO}-\mathrm{BaO}$ glasses. J. Non-Cryst. Solids, 358, 947-951, http://dx.doi.org/10.1016\%2Fj.jnoncrysol.2012.01.003.

10. Sekiya, T., Mochida, N. \& Ohtsuka, A. (1994). Raman spectra of MO$\mathrm{TeO}_{2}(\mathrm{M}=\mathrm{Mg}$, Sr, Ba and Zn) glasses. J. Non-Cryst. Solids, 168, 106114, http://dx.doi.org/10.1016/0022-3093(94)90125-2.

11. Sekiya, T. et al. (1992). Raman spectra of $\mathrm{MO}_{1 / 2}-\mathrm{TeO}_{2}(\mathrm{M}=\mathrm{Li}, \mathrm{Na}, \mathrm{K}$, $\mathrm{Rb}, \mathrm{Cs}$ and $\mathrm{Tl}$ ) glasses. J. Non-Cryst. Solids, 144, 128-144, http://dx.doi.org/10.1016/S0022-3093(05)80393-X.

12. Sharaf, J. M. \& Saleh, H.(2015). Gamma-ray energy buildup factor calculations and shielding effects of some Jordanian building structures. Radiat. Phys. Chem.,110, 87-95, http://dx.doi.org/10.1016/ j.radphyschem.2015.01.031.

13. Salehi, D., Sardari, D. \& Jozani, M. (2015). Investigation of some radiation shielding parameters in soft tissue. J. Radiat. Res. Appl. Sci., 8, 439-445, http://dx.doi.org/10.1016/j.jrras.2015.03.004.

14. Harima, Y. et al. (1986). Validity of the geometric-progression formula in approximating gamma-ray buildup factors. Nucl. Sci. Eng., 94, 24-35.

15. Suteau, C. (2005). An iterative method for calculating gamma-ray buildup factors in multi-layer shields. Radiat. Prot. Dosim., 116, 489-492, http://dx.doi.org/10.1093/rpd/nci192.

16. Shimizu, A. (2002). Calculation of gamma-ray buildup factors up to depths of $100 \mathrm{mfp}$ by the method of invariant embedding. (I). Analysis of accuracy and comparison with other data. J. Nucl. Sci. Technol., 39, 477-486, http://dx.doi.org/10.1080/18811248.2002.9715225.

17. Shimizu, A., Onda, T. \& Sakamoto, Y. (2004). Calculation of gamma-ray buildup factors up to depths of $100 \mathrm{mfp}$ by the method of invariant embedding. (III). Generation of an improved data set. J. Nucl. Sci. Technol., 41, 413-424, http://dx.doi.org/10.1080/18811248.2004. 9715503.

18. Sardari, D. et al. (2009). Estimation of gamma- and X-ray photons buildup factor in soft tissue with Monte Carlo method. Appl. Radiat. Isot., 67, 1438-1440, http://dx.doi.org/10.1016/j.apradiso.2009.02.033.

19. American National Standard, ANS. (1991). ANSI/ANS-6.4.3: Gamma ray attenuation coefficient and buildup factors for engineering materials. New York: ANS.

20. Singh, V. P., Badiger, N. M. \& Kaewkhao, J. (2014). Radiation shielding competence of silicate and borate heavy metal oxide glasses: Comparative study. J. Non-Cryst. Solids, 404, 167-173, http://dx.doi.org/10.1016/j.jnoncrysol.2014.08.003. 
21. Chanthima, N. \& Kaewkhao, J. (2013). Investigation on radiation shielding parameters of bismuth borosilicate glass from $1 \mathrm{keV}$ to $100 \mathrm{GeV}$. Ann.Nucl. Eng., 55, 23-28, http://dx.doi.org/10.1016/j.anucene.2012. 12.011 .

22. Singh, K. J., Kaur, S. \& Kaundal, R. S. (2014). Comparative study of gamma ray shielding and some properties of $\mathrm{PbO}-\mathrm{SiO}_{2}-\mathrm{Al}_{2} \mathrm{O}_{3}$ and $\mathrm{Bi}_{2} \mathrm{O}_{3}-$ $\mathrm{SiO}_{2}-\mathrm{Al}_{2} \mathrm{O}_{3}$ glass systems. Radiat. Phys. Chem., 96, 153-157, http://dx.doi.org/10.1016/j.radphyschem.2013.09.015.

23. Ruengsri, S. et al. (2015). Development of barium borosilicate glasses for radiation shielding materials using rice husk ash as a silica source. Prog. Nucl. Energy, 83, 99-104, http://dx.doi.org/10.1016/j.pnucene.2015. 03.006 .

24. Singh, V. P. et al. (2014). Evaluation of gamma-ray exposure buildup factors and neutron shielding for bismuth borosilicate glasses. Radiat. Phys. Chem., 98, 14-21, http://dx.doi.org/10.1016/j.radphyschem. 2013.12.029.

25. Kurudirek, M. (2014). Radiation shielding and effective atomic number studies in different types of shielding concretes, lead base and non-lead base glass systems for total electron interaction: A comparative study. Nucl. Eng. Des., 280, 440-448, http://dx.doi.org/10.1016/j.nucengdes. 2014.09.020.

26. Burger, H., Vogel, W. \& Kozhukharov, V. (1985). IR transmission and properties of glasses in the $\mathrm{TeO}_{2}-\mathrm{RnOm}, \mathrm{RnXm}, \mathrm{Rn}\left(\mathrm{SO}_{4}\right) \mathrm{m}, \mathrm{Rn}\left(\mathrm{PO}_{3}\right) \mathrm{m}$ and $\left[\mathrm{B}_{2} \mathrm{O}_{3}\right]$ systems. Infrared Phys., 25, 395-409, http://dx.doi.org/ 10.1016/0020-0891(85)90114-9.

27. Sidek, H. et al. (2004). Formation and elastic behavior of leadmagnesium chlorophosphate glasses. Turkish J. Phys., 28, 65-71.

28. Sidek, H. et al. (2009). Synthesis and optical properties of $\mathrm{ZnO}^{-\mathrm{TeO}_{2}}$ glass system. Am. J. App. Sci., 6, 1489-1494, http://dx.doi.org/ 10.3844/ajassp.2009.1489.1494.

29. Gerward, L. et al. (2001). X-ray absorption in matter. Reengineering XCOM. Radiat. Phys. Chem., 60, 23-24, http://dx.doi.org/10.1016/ S0969-806X(00)00324-8.

30. Gerward, L. et al. (2004). WinXCom - A program for calculating X-ray attenuation coefficients. Radiat. Phys. Chem., 71, 653-654, http://dx.doi.org/10.1016/j.radphyschem.2004.04.040.

31. Harima, Y. (1983). An approximation of gamma-ray buildup factors by modified geometrical progression. Nucl. Sci. Eng., 83, 299-309.

32. Harima, Y. (1993). An historical review and current status of buildup factor calculations and applications. Radiat. Phys. Chem., 41, 631-672, http://dx.doi.org/10.1016/0969-806X(93)90317-N. 
33. Bootjomchai, C. et al. (2012). Gamma-ray shielding and structural properties of barium-bismuth-borosilicate glasses. Radiat. Phys. Chem., 81, 785-790, http://dx.doi.org/10.1016/j.radphyschem.2012.01.049.

34. Kurudirek, M. \& Zdemir, Y. (2011). Energy absorption and exposure buildup factors for some polymers and tissue substitute materials: Photon energy, penetration depth and chemical composition dependence. J. Radiol. Prot., 31, 117-128, http://dx.doi.org/10.1088/0952-4746/31/ $1 / 008$. 